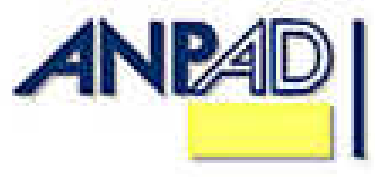

Disponível em

http://www.anpad.org.br/rac

RAC, Curitiba, v. 15 , n. 6, art. 4,

pp. 1040-1058, Nov./Dez. 2011

$((\mathrm{cc}) \mathrm{EY}-\mathrm{NG}$

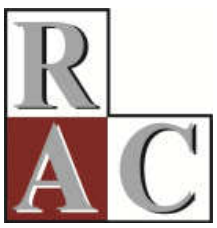

\title{
Administração Pública de Québec: um Caso de Mudança Cultural
}

\author{
The Public Administration of Quebec: in Search of a Cultural Change
}

Lindomar Pinto da Silva *

E-mail: lpsilva@sefaz.ba.gov.br Faculdade Anísio Teixeira - FAT

Feira de Santana, BA, Brasil.

Élvia Fadul E-mail: elvia@unifacs.br Universidade Salvador - UNIFACS

Feira de Santana, BA, Brasil.

* Endereço: Lindomar Pinto da Silva

Rua Adenil Falcão, 1823; Bairro Brasília, Cidade Feira de Santana/BA, 44088-744.

Copyright (C) 2011 RAC. Todos os direitos, até mesmo de tradução, são reservados. É permitido citar parte de artigos sem autorização prévia, desde que seja identificada a fonte. 


\title{
Resumo
}

Neste artigo procurou-se identificar os traços culturais da administração pública de Québec, além de verificar mudanças culturais ocorridas a partir da reforma administrativa levada a efeito nessa província canadense a partir dos anos 1990. Utilizou-se como conceito de cultura um conjunto de valores e artefatos, cujos significados orientam o comportamento dos indivíduos, e de que ela é passível de mudança por processos de aprendizagem cultural (Davel, Dupuis, \& Chanlat, 2008; Sainsaulieu, 1977). A metodologia de pesquisa foi a análise de discurso baseada nas dimensões das figuras e temas presentes nos discursos (Fiorin, 2008). Os dados foram coletados em livros e artigos publicados nos principais periódicos canadenses, com destaque para as publicações da École Nationale d'Administration Publique (ENAP, Québec). Foram utilizados também documentos do governo de Québec disponíveis no site web, além de entrevistas com 3 (três) pesquisadores da ENAP. Verificouse que a cultura organizacional ocupou espaço importante nos objetivos de mudanças na reforma administrativa e que há um processo de mudança cultural em curso. Temas como profissionalização, igualdade e flexibilidade começam a integrar as representações coletivas dos indivíduos nas organizações públicas desta província.

Palavras-chave: cultura organizacional; mudança cultural; administração pública; Québec.

\begin{abstract}
In this article we attempted to identify the cultural traits of the public administration of Quebec, in addition to reviewing the cultural changes that occurred following the administrative reform that came into effect in this Canadian province in the 1990s. As a concept of culture we used a set of values and artifacts whose meanings guide the behavior of individuals and is subject to changes through cultural learning processes (Davel, Dupuis, \& Chanlat, 2008; Sainsaulieu, 1977). The research methodology used was the discourse analysis based on the dimensions of figures and themes that are present in the discourses (Fiorin, 2008). The data were collected from books and articles published in the main Canadian journals, with emphasis on the publications of the École Nationale d'Administration Publique (ENAP, Quebec). Documents of the Quebec government that were available on the website were also used, in addition to interviews given by 3 (three) ENAP researchers. It was shown that organizational culture occupied an important space in the objectives of changes in the administrative reform and that there is an ongoing process of cultural change. Topics such as professionalization, equality and flexibility have begun to become part of the collective representations of the individuals in the public organizations of this province.
\end{abstract}

Key words: organizational culture; cultural change; public administration; Quebec. 


\section{Introdução}

Ao longo das últimas décadas, principalmente a partir dos anos 1990, com os processos de reforma que sacudiram as nações, a administração pública passou por transformações significativas. Seja pela constatação de que os Estados nacionais não mais conseguiam dar conta das suas atribuições em função das crises e dos desequilíbrios financeiros, seja por pressões do capital internacional, as reformas se sucederam em modelos que variavam de um discurso sobre a necessidade de redefinição do seu papel, até o completo desmonte do próprio Estado com processos de privatização ou compartilhamento das atividades estatais com o setor privado. Da redução do tamanho do Estado, transferindo-se atividades e empresas públicas para o setor privado, até a modificação das formas de gerenciar o próprio Estado com reformas administrativas que buscavam introduzir, no setor público, os padrões de eficiência existentes na iniciativa privada, diversas dimensões das organizações públicas foram alvo de mudanças, e entre estas, encontra-se a dimensão cultural, foco deste trabalho.

Para tanto, elegeu-se a administração pública da província de Québec como universo desta análise, porquanto sua cultura organizacional foi objeto de atenção desde o início das reformas administrativas. Esta preocupação pode ser observada tanto no governo federal, com a instituição da Fonction Publique 2000 (Ministère des Approvisionnements et Services [MAS], 1990), quanto especificamente em Québec com a Déclaration de valeurs de l'administration publique québécoise (Secrétariat du Conseil du Trésor [SCT], 2010). Assim, percebe-se entre os pesquisadores de Québec que a cultura organizacional é alvo de análises aprofundadas, ao longo dos processos de reforma, podendo-se mencionar, por exemplo, Mazouz (2008), Mazouz e Tardif (2009), Bernier (2003), Proulx (2003, 2005, 2008, 2009). Proulx (2003) por sua vez, destaca que:

Esta faceta da modernização das administrações é, portanto, uma transformação fundamental das organizações públicas para aumentar a sua eficácia, sua eficiência, sua adaptabilidade e sua capacidade de inovar. Como qualquer outra é uma mudança cultural mais do que apenas estrutural, o que reforça a importância de analisar esta dimensão (Proulx, 2003, p. 40).

Para compreender a dimensão cultural na administração pública de Québec inicia-se este artigo com breve discussão sobre cultura organizacional. Descreve-se, em seguida, a metodologia da pesquisa, para então apresentar as principais discussões da cultura e da mudança cultural ocorridas na província de Québec, Canadá, que ajudam a compreender como os estudos culturais buscam desvendar os aspectos culturais na administração pública desta província. Por fim, apresenta-se uma conclusão na qual se destacam as principais contribuições que esses estudos podem trazer, para compreender outras realidades nacionais, ressalvando que, por tratar-se de cultura organizacional, as especificidades de cada cultura devem ser respeitadas.

Cabe lembrar que o Canadá é uma federação constituída por 10 províncias e 3 territórios, com um sistema de governo parlamentarista, em uma monarquia constitucional. Compõem a organização político-administrativa da província de Québec, cuja capital é Cidade de Québec, vários organismos que são denominados ministérios, secretarias, comissões e conselhos entre outros. Por coerência, nas referências feitas a esses organismos no âmbito da província de Québec, essas mesmas denominações foram mantidas, pois se considerou que, procurar estabelecer uma correspondência dos ministérios com as secretarias estaduais existentes na organização político-administrativa brasileira, poderia ocasionar distorções de âmbito e nível com relação aos demais organismos. Já no caso do órgão legislativo da província, apesar de ser denominado Assemblée Nationale (Assembleia Nacional), por ser apenas um órgão e uma instância, esta será referenciada como a Assembleia Legislativa. 


\section{Cultura Organizacional: Breves Discussões}

Para iniciar e orientar a discussão sobre cultura, além de reforçar a importância deste constructo, que foi incorporado nos estudos organizacionais e ainda continua sendo uma dimensão organizacional fundamental para a compreensão da vida organizacional, destaca-se a afirmação de que:

Toda comunicação humana depende de significados compartilhados a fim de conseguir assegurar um mínimo de coordenação e de colaboração dos indivíduos. Se sentido e significado constituem as unidades básicas de ordem cultural (Geertz, 1973; Sahlins, 1976), podemos considerar a gestão como uma atividade profundamente cultural (Davel et al., 2008, p. 1).

O tema cultura organizacional ganhou evidência a partir dos anos 1980 e, apesar das diversas abordagens que tratam deste constructo, ele se inseriu na agenda de pesquisa porque, segundo se depreende de alguns estudos culturais (Alvesson, 2007; Deal \& Kennedy, 2000; Schein, 2004), a cultura pode determinar a razão dos comportamentos dos indivíduos nas organizações. Diversos são os fatores que podem justificar esta ascensão do tema, conforme indica Aktouf (1990). Apesar disso, Bonnafous-Boucher (2005) entende que a apreensão do conceito de cultura na gestão pode ser benéfica tanto para a antropologia, de onde o conceito se origina, como para a gestão, desde que não se faça da cultura um instrumento gerencial.

O trabalho de Sainsaulieu (1977), por exemplo, permite incluir entre os elementos culturais, os valores, ideologia, mitos e regras. Também é possível perceber, como se dão os processos de aprendizagem cultural e o papel que a tentativa de construção de mitos organizacionais têm, para modificar as formas de dominação no ambiente organizacional. Outros autores incluem os símbolos e significados culturais no conceito de cultura ou, pelo menos, entendem que esses elementos são importantes na compreensão da cultura, como é o caso de Dupuis (1990), ao afirmar que toda compreensão de cultura deve necessariamente ser pensada a partir das práticas dos atores, as significações que estas práticas engendram e o contexto em que elas ocorrem.

Para Alvesson (2007), que defende a importância simbólica ao modo de Geertz (1989), cultura é "um sistema mais ou menos coeso de significados e símbolos, em termos dos quais as interações sociais têm lugar" (Alvesson, 2007, p. 5). Sainsaulieu (2001, p. 25) define-a como "o reservatório interiorizado, transmitido e cuidadosamente elaborado pela história, de um conjunto de valores, de regras e representações coletivas que são profundas nas relações humanas".

Dos elementos da cultura organizacional destacados acima, alguns serão brevemente tratados por serem utilizados mais detidamente neste trabalho: os artefatos visíveis (normas escritas, estruturas, rituais) e os valores organizacionais. Os artefatos são os elementos da cultura que podem ser vistos, sentidos e ouvidos. Incluem os produtos, estrutura física, linguagem, tecnologia, roupas, mitos, histórias, lista de valores publicados, rituais e cerimônias. Por isso, são facilmente visíveis. Incluem-se nesta lista, conforme Martin (2002, p. 65) os jargões, humores, e os códigos de vestimentas.

Schein (2004) considera que estes elementos são de fácil visualização, mas de difícil interpretação. Sackmann (1992) considera que os significados dos artefatos estão localizados em níveis mais profundos da compreensão cultural, sendo, portanto, difíceis de serem apreendidos e compreendidos. Porém Sackmann (1992) defende que os artefatos são importantes porque, de fato, eles expressam significados atribuídos pelos membros da organização. A dificuldade reside, entre outros motivos, no fato de que as mesmas manifestações e artefatos podem ter significados diferentes para os membros da mesma organização, além de que alguns artefatos podem existir apenas como "rotinas ultrapassadas, que pertencem a uma era passada cujos significados não são mais relevantes para o grupo dominante dos atores organizacionais" (Sackmann, 1992, p. 142). Por isso a compreensão dos significados culturais dos artefatos exige atenção adequada do pesquisador, caso ele deseje compreender, em sua maior inteireza, os significados dos artefatos organizacionais. 
Deal e Kennedy (2000) afirmam que os artefatos possuem uma função específica, que é a criação ou manutenção de valores necessários à vida organizacional. Entretanto, no modo da visão interpretativa da cultura (Geertz, 1989), os artefatos culturais são representações simbólicas daquilo que os membros da organização compartilham sobre sua cultura. Os valores organizacionais são menos claros e mais difíceis de serem até mesmo observados e interpretados. Eles são orientadores do comportamento dos indivíduos nas organizações e constituem-se no elemento fundamental da análise da cultura organizacional (Schein, 2004).

Deal e Kennedy (2000, p. 21) definem valor com "pano de fundo de qualquer cultura corporativa. Como a essência da filosofia da companhia para a realização do sucesso, os valores servem de senso de direção comum para todos os empregados e guia de comportamento para seu dia a dia”. Schwartz (1994) compartilha com aqueles autores sobre a importância dos valores, definindo-os como "crenças relacionadas à emoção que guiam a seleção e avaliação de ações, pessoas e eventos. Eles são ordenados pela importância relativa aos demais, constituindo sistema ordenado de prioridades axiológicas de cada ser humano" (Schwartz, 1994, p. 20).

O que se depreende destas definições é que os valores servem para motivar os comportamentos humanos. Neste sentido, Hofstede (1991, p. 23) considera os valores "como uma tendência para preferir certos posicionamentos e comportamentos e não outros, e que estes elementos são o centro da cultura". Machado-da-Silva e Nogueira (2000, p. 11), em certa medida, concordam com a visão de Hofstede, quando consideram os valores como "padrões de julgamento, cujos significados compartilhados indicam o preferível ou desejável, e podem expressar a ideia de como deve ser ou deveria ser a realidade, a idealização ou o ideal". Nas organizações, os valores normalmente integram sua declaração de valores. Parte-se da ideia, defendida por Schein (2004) e Kotter e Heskett (1992), de que ao definir e declarar valores e divulgá-los, a prática favorecerá a sua internalização.

Assim, neste trabalho, a análise apoia-se nos elementos materiais insertos nas organizações públicas, constituindo-se em artefatos visíveis, e nos valores organizacionais disseminados por elas. Na medida em que os artefatos vão sendo insertos nas organizações, espera-se, na visão dos gestores, e de acordo com a perspectiva funcionalista da cultura, que os indivíduos assimilem os valores associados a tais artefatos, passando a comportar-se de acordo com as orientações destes.

\section{Metodologia}

Este trabalho caracteriza-se como qualitativo e descritivo, na medida em que, nas análises qualitativas dos dados, buscou descrever um processo de mudança cultural. Os dados foram coletados entre os meses de março e junho de 2010, durante realização de estágio de doutorado de um dos autores no Canadá. Para a coleta dos dados, foram feitas buscas nos principais periódicos publicados pela École Nationale d'Administration Publique (ENAP), a exemplo do Observgo, Parallèle, Télescope, Vigie e Coup d'oeil, utilizando-se como chamada o tema cultura organizacional em organizações públicas. Também foram analisados os artigos publicados pela Revue d'Administration Publique do Canada, publicada pelo Institut d'Administration Publique du Canada e no periódico Management International publicado pela École des Hautes Études Commerciales de Montreal. A coleta de dados também envolveu a realização de 3 entrevistas semiestruturadas, com pesquisadores da ENAP, em Quebec, entrevistas que duraram em torno de 1 hora e cuja publicação foi devidamente autorizada pelos entrevistados. Para completar o processo de levantamento de dados, foram consultados livros, bem como documentos do governo da província de Quebec, principalmente os disponíveis no seu site web. O período analisado abrange os anos de 1990 a 2010, que representa um espaço de tempo em que as ações da reforma administrativa foram implementadas nesta província.

A análise dos dados foi feita utilizando a Análise de Discurso, nas dimensões das figuras e temas descritas por Fiorin (2008). O discurso, segundo Fiorin (2007, p. 55), "contém em si, como parte da visão de mundo que veicula, um sistema de valores, isto é, estereótipos dos comportamentos 
humanos, que são valorizados positiva ou negativamente". Além disso, Grant, Hardy, Oswick e Putnan $(2004$, p. 3), mostrando a relação entre discurso e cultura, definem o discurso como "uma coleção de textos incorporados em práticas de fala e textos (tanto quanto em ampla variedade de representações visuais e artefatos culturais) que tanto estão relacionados a objetos como à forma em que aqueles textos são produzidos, disseminados e consumidos". A figura é o termo que remete a algo existente no mundo material (árvore, sol, brincar, plano de carreira, estrutura, curso, seleção por concurso, etc.), enquanto o tema é um investimento semântico, de natureza conceitual, que não remete ao mundo natural. "São categorias que organizam, categorizam e ordenam os elementos do mundo natural: calculista, orgulhoso, honesto, meritocracia, igualdade etc." (Fiorin, 2007, p. 91).

Assim, em cada discurso analisado foram encontradas diversas figuras inseridas no contexto das organizações públicas; estas figuras representam os novos temas ou valores que se pretendem ver incorporados ao imaginário simbólico dos servidores públicos dessa província. Ao utilizar os discursos como base para a análise dos dados, este trabalho comunga com a perspectiva de Alvesson (2004), quando afirma:

os discursos são ordenados e integrados pelas culturas, mas também representam (talvez o mais importante) meio no qual as culturas são construídas, reproduzidas, contestadas e modificadas. No discurso, ideologias e outros elementos culturais são desenvolvidos, modificados e expressos. Neste nível é que o sujeito é atingido pelos atos lingüísticos, carregando e aplicando temas culturais e ideologias mais ou menos fragmentadas e elaboradas (Alvesson, 2004, p. 331).

Além disso, entende-se que a análise de discurso é um método importante de análise organizacional, tendo em vista que o discurso revela as principais características da organização.

\section{Contexto e Análise dos Dados}

A província de Québec inicia seu programa de modernização com um conjunto de princípios e compreende que os aspectos culturais são fundamentais, principalmente no que se refere à necessidade de mudanças desses fatores. Quando se analisam os textos oriundos dos projetos de reforma, bem como a literatura produzida a partir deles, a cultura organizacional e, mais precisamente os valores culturais, assumem importância significativa. Entre as mudanças previstas na reforma administrativa de Québec podem destacar-se: "a prestação de contas pelos gestores, a escolha da forma de gestão, alguns objetivos expressos pelos cidadãos; foco nos resultados em função dos objetivos, flexibilidade e utilização ótima dos recursos da administração governamental" (Lei n. 82, 2000).

Todos estes objetivos têm desdobramentos diversos, principalmente no que se refere à gestão por resultados, uma vez que, a partir dela, os gestores são obrigados não só a prestar um bom serviço, com menor custo, com satisfação dos clientes, mas ainda prestar contas de sua gestão. Percebe-se que a mudança cultural é o elemento fundamental na passagem de uma gestão baseada na burocracia, com foco no cumprimento das regras, para uma gestão com avaliação a posteriori. Para Mazouz (2008) a mudança consistiria em transformar a cultura, porque o grande foco da mudança se concentra no comportamento dos gestores, o que seria resultado dos valores. É interessante notar que Mazouz (2008), quando discute os novos papéis do gestor, a partir das mudanças trazidas pelas reformas administrativas, dedica-se a descrever aspectos culturais importantes, para que esse processo tenha sucesso. Para o autor, esses processos de mudanças colocam o gestor em nova dimensão que exige mudanças importantes em sua forma de pensar e na cultura:

A evolução da função de gestor público, como discutida nesta coletânea, é abordada neste capítulo como uma adaptação de papéis e de funções exercidas à luz do conceito de desempenho: o (desempenho) dos resultados, e não o (desempenho) dos meios. Desse modo, abordamos a mudança cultural que os indicadores de medição e avaliação, intimamente ligados ao desempenho, articulam para atingir diretamente o gestor público na sua expressão 
profissional e no seu valor; aquele (desempenho) que desestabiliza as bases weberianas de uma função padronizada, repetitiva, processual e protocolar (Mazouz, 2008, p. 17).

Desta forma, inicia-se esta parte do trabalho, buscando caracterizar aspectos culturais das organizações públicas em Québec, a partir de 1990. Neste sentido, merecem destaque as pesquisas de Julien (1993), Chanlat (1984), Boisvert (1997) e Lozeau (2005). Outros estudos também merecem destaque pela análise do que poderia ser o conjunto de características da gestão pública no início da reforma, como os trabalhos de Mazouz (2008), Mazouz e Tardif (2009), Lemay (2008) e Symons (1992). Apesar de estes trabalhos não terem como base pesquisas de campo, suas análises pressupõem a existência de características indesejadas na administração pública que devem ser eliminadas.

\section{Igualdade de Oportunidades como Valor Cultural das Organizações Públicas em Québec}

Como acontece em diversas sociedades, as diferenças de sexo, raça e religião servem de base para os processos discriminatórios, o que faz com que alguns grupos, chamados de minorias, sejam marginalizados nos principais processos sociais. Neste sentido, percebeu-se primeiro no contexto federal (MAS, 1990), e em seguida no nível da província (Lei n. 82, 2000) uma indicação de que o valor igualdade deveria nortear o comportamento da função pública. Na Tabela 1 a seguir é possível verificar que, das amostras utilizadas pelos pesquisadores ao longo deste período, o percentual de mulheres nos quadros de gestão tem aumentado significativamente, ou pelo menos é representativo.

Tabela 1

Participação Feminina nos Quadros Gerenciais de Québec

\begin{tabular}{lcccc}
\hline \multicolumn{1}{c}{ Fonte } & Ano & Tamanho da amostra & Homens (\%) & Mulheres (\%) \\
\hline Julien & 1993 & 1272 & 87,90 & 11,80 \\
Boisvert & 1997 & 883 & 62,00 & 34,00 \\
Boisvert & 1997 & 465 & 66,02 & 33,98 \\
Proulx & 2003 & 111 & 55,86 & 44,14 \\
$\begin{array}{l}\text { Dallaire (número de ministros } \\
\text { em Québec) }\end{array}$ & 2006 & 26 & 61,54 & 38,46 \\
$\begin{array}{l}\text { Conselho de Ministro de } \\
\text { Québec (número de ministros) }\end{array}$ & 2010 & 27 & 55,17 & 44,83 \\
\hline
\end{tabular}

Fonte: elaboração própria.

No âmbito do governo do Canadá, há uma declaração da necessidade de a função pública possibilitar melhorar as condições de acessibilidade ao trabalho público das mulheres e dos grupos minoritários (MAS, 1990); o governo de Québec procurou incluir este item nas questões mais amplas dos grupos minoritários pela Lei n. 82 (2000), conforme reza o artigo 35: "O Conselho do Tesouro criou alguns programas de acesso à igualdade aplicáveis à função pública com vistas a corrigir a situação das pessoas que fazem parte de grupos discriminados no mercado de trabalho" (Lei n. 82, 2000, art. 35). 


\section{Poder e Relações Hierárquicas}

O trabalho de Lozeau (2005), apesar de ter sido publicado em 2005, destaca aspectos culturais de um período muito anterior. Sua pesquisa começa a partir de 1995 e vai até o ano 2000. Neste trabalho, o autor analisa a implantação do programa de Gestão da Qualidade em 8 (oito) hospitais públicos de Québec. Suas análises orientam-se no sentido de buscar compreender os aspectos que levaram a implementação do programa ao fracasso. A primeira questão destacada por Lozeau (2005) refere-se ao fato de que a forma pela qual o programa foi imposto, seguindo um modelo federal, e sob a supervisão deste governo, teria sido o primeiro problema enfrentado no processo de implementação do programa.

As relações de poder pareciam estar ameaçadas; em função disso, as propostas de alteração foram sendo rechaçadas pelos membros dos hospitais, principalmente aqueles que faziam parte dos níveis gerenciais e pelos médicos. Lozeau (2005) menciona não só o descaso de alguns diretores de hospitais ao programa, mas também o boicote aberto, em função da possibilidade de horizontalização da organização, que significaria redução do poder que esses diretores mantinham. O estudo de Lozeau (2005) evidencia dois aspectos principais: a centralização do poder e o corporativismo dos grupos, na medida em que procuravam meios para manter seu statu quo. Diz Lozeau (2005, p. 110):

Os grupos internos demonstraram pouco entusiasmo pela implantação do programa gestão da qualidade, mas as resistências mais fortes vieram dos atores que temiam perder sua capacidade de agir livremente (como os médicos), de exercer mais dificilmente sua autoridade e de precisar adotar novos esquemas de comportamentos (tais como vários administradores) (Lozeau, 2005, p. 110).

Outro estudo que serve de orientação para analisar os aspectos culturais da gestão pública em Québec no início dos processos de reforma é o trabalho do Julien (1993). Buscando compreender as características culturais dos gestores, este autor aplicou um questionário a 1.272 gestores. O objetivo de Julien (1993, p. 319) era "conhecer os valores reais da gestão que guiam os ministérios e os organismos governamentais na definição de seus objetivos e na elaboração das regras de conduta de seu pessoal". Para este autor, os valores culturais são responsáveis pelo comportamento dos atores organizacionais. São estes valores que definem as estratégias, as relações internas; em tese, as ações do governo são, em primeiro lugar, uma questão de valores. Julien (1993) apresentou aos indivíduos uma lista com 60 afirmativas, indicando os valores associados a cada uma destas afirmativas. As afirmativas foram agrupadas na Tabela 2, a seguir.

Tabela 2

\section{Categorias de Valores Identificados nas Organizações Públicas}

\begin{tabular}{ll}
\hline Categorias de valores & Valores \\
\hline Valores de gestão & $\begin{array}{l}\text { serviço ao cliente, desempenho no trabalho, excelência, poder da organização, } \\
\text { inovação, economia de recursos, eliminação do desperdício, competência, } \\
\text { conforto do pessoal }\end{array}$ \\
\hline $\begin{array}{l}\text { Valores associados à conduta } \\
\text { dos membros }\end{array}$ & $\begin{array}{l}\text { engajamento em prol da organização, espírito de colaboração, relações } \\
\text { hierárquicas, flexibilidade da direção e liberdade profissional }\end{array}$ \\
\hline
\end{tabular}

Fonte: elaborado a partir de Julien, G. (1993). Les valeurs collectives de gestion dans la fonction publique Québécoise: la perception des cadres (p. 319). Revue d'Administration Publique du Canada, 36(3), 319-348. doi: 10.1111/j.17547121.1993.tb01957.x

Julien (1993) utilizou uma metodologia na qual para cada questão o respondente tinha a opção de escolher entre totalmente falso, muito falso, muito verdadeiro, absolutamente verdadeiro. Os resultados apresentados pelo autor sugerem algumas questões muito interessantes, no que se refere aos 
valores na visão dos gestores. Evidenciam que há alguns valores que estão fortemente presentes na percepção dos gestores e que há outros valores que estão ausentes. $\mathrm{O}$ autor ressalta que valores tais como serviço à clientela, desempenho no serviço, excelência, eliminação do desperdício, espírito de colaboração e liberdade profissional não se destacaram como sendo fortemente percebidos pelos gestores públicos na sua ação diária.

Três outros valores merecem um comentário. O primeiro deles é a inovação. Descrito nos processos de reforma como fator importante de sucesso organizacional, este valor não foi fortemente observado por Julien, segundo a percepção dos gestores. Outro valor que merece destaque são as relações hierárquicas. Também este teve pontuações muito baixas, o que pode significar que há fraca valorização das relações hierárquicas nas organizações públicas de Québec. De certa forma, essa situação foi observada nos trabalhos de Dupuis e Davel (2004) e Proulx (2003, 2008), indicando que a sociedade na província de Quebec parece não reproduzir o modelo de relações hierárquicas estabelecidas em regiões como a América Latina, onde as relações hierárquicas são fortemente valorizadas (Davel, Dantas, \& Vergara, 2008; Hofstede, 2001).

O terceiro aspecto é a flexibilidade do trabalho dos gestores. Gestão por resultados exige do gestor elevado grau de flexibilidade, pois as regras existentes são importantes, mas os resultados, a mobilização das pessoas e dos recursos são, talvez, ainda mais importantes (Lemay, 2008; Mazouz, 2008). Outros destaques negativos ficam por conta do espírito de colaboração e o engajamento em prol da organização, que não teriam sido encontrados na pesquisa de Julien (1993).

Uma preocupação é manifestada na análise de Julien: mesmo os valores mais bem avaliados guardam relação importante com a proximidade do poder central. Segundo Julien (1993), quanto mais distante do ministro ou do chefe da organização, menos as pessoas estão envolvidas com a organização. Essa constatação de que as pessoas mais distantes do poder central se envolvem menos com a organização parece contraditória também com a ideia das relações hierárquicas. A conclusão parece lógica: as relações hierárquicas são importantes para a melhoria da colaboração e para o engajamento em prol da organização; logo não se pode subestimar o valor atribuído pelos gestores às relações de poder estabelecidas nessas organizações. Esta análise é interessante, porque o discurso de baixa valorização das relações de poder vai reproduzir-se em trabalhos mais recentes (Lemay, 2008; Proulx, 2005, 2008).

Outro estudo que merece destaque pela análise inicial dos aspectos característicos da administração pública em Québec é o de Boisvert (1997). Dividindo o estudo em duas etapas, o autor utilizou duas amostras para investigar o conjunto de valores mais presentes na percepção dos gestores públicos desta província. Uma amostra continha 883 gestores e a outra, 465. Para a primeira amostra ele usou o método de apreciação por simulação (APS) e para a segunda, utilizou método o MBTI (indicador de tipos psicológicos de Briggs e Meyers) (Boisvert, 1997).

Ele construiu uma escala de valores que variavam de 1 (cuja interpretação significa presença nula ou ausência total do valor) até 10 (que indica presença plena do valor). As competências ou valores foram divididos em quatro grandes categorias, a saber: características pessoais, características intelectuais, características relacionais e características gerenciais. O melhor resultado para Boisvert (1997) é um número acima de 6,0. A análise do trabalho do Boisvert (1997) permite uma compreensão extremamente rica do ponto de vista do conhecimento dos principais valores que orientavam os gestores públicos da província de Québec também no início das reformas administrativas.

\section{Nova Cultura Organizacional na Administração Pública de Québec?}

A partir deste tópico, procura-se mostrar análises realizadas em trabalhos que revelam novos aspectos culturais das organizações públicas de Québec. Procura-se aqui, no modo do que até então foi tratado, descrever o que têm revelado as novas pesquisas sobre o tema da cultura nessas organizações. 
Proulx e Bière (2005) mostram o novo discurso de diretores de recursos humanos sobre as mudanças já percebidas, a partir das reformas implementadas. Esses autores chamam de cultura profissional e cultura de empresa as novas culturas desenvolvidas, a partir dos processos de reforma. Alguns extratos das entrevistas realizadas por esses autores ajudam a reforçar essa percepção:

A qualidade do trabalho, o rigor e a independência são frequentemente justapostos a este tipo de cultura. É uma cultura ao mesmo tempo de rigor e de flexibilidade. Trata-se de uma cultura primeiramente de independência (Proulx \& Bière, 2005, p. 65).

A cultura atualmente é uma cultura aberta. Ela é baseada em resultados, mas levando em conta a pessoa, no seu interior. Este é um ministério que tem uma cultura de ação. É um ministério muito ativo e também inovador (Proulx \& Bière, 2005, p. 66).

Esses extratos de entrevistas utilizados por Proulx e Bière (2005) demonstram sinais diferentes dos que foram apresentados por Julien (1993), Boisvert (1997) e Lozeau (2005). Percebe-se, nestes discursos, temas que não apareciam nos textos anteriores. Surgem temas como independência e flexibilidade em confronto com os rigores burocráticos, bem como o tema da preocupação com as pessoas aparece em lugar da falta de capacidade de ouvir dos chefes antigos. O tema da inovação também começa a se evidenciar.

Julien (1993) fala de falta de conhecimento das demandas dos clientes. Entretanto, Proulx e Bière (2005, p. 69) já sinalizam que os dirigentes já "aprendem que a taxa de satisfação dos clientes já está elevada e que eles utilizam dados específicos para identificar as necessidades de melhoria". Esse é um processo importante de mudança. Mesmo que nos discursos do cotidiano no passado se falasse de clientela, Julien (1993) demonstra que havia pouca ação neste sentido. No trabalho de Boisvert (1997), ainda que ele não tenha avaliado este aspecto diretamente, pode-se deduzir que, ao priorizar relativamente pouco a atenção ao ambiente, os gestores estariam pouco envolvidos com as demandas de seus clientes. Entretanto, já neste trabalho de Proulx e Bière (2005), percebe-se uma evolução deste aspecto da gestão.

Quando se analisa de igual modo a Lei que trata da Função Pública, percebe-se outro conjunto de valores que devem estar presentes nas relações estabelecidas nas organizações públicas em Quebec: eficiência na utilização dos recursos humanos, desenvolvimento pessoal, redução das hierarquias, prestação de contas, igualdade de acesso à função pública, imparcialidade, abertura para a recepção de contribuições da sociedade (Lei n. 82, 2000). Então, até este momento, é possível perceber o alinhamento dos discursos entre o que a administração pública espera de seus servidores e os discursos dos gestores. Por fim, retomando a fala de Julien (1993) e do entrevistado A, a proximidade com o poder influencia o discurso, porque segundo este entrevistado, "é necessário ter cuidado com o discurso, já que a cultura é difícil de mudar, mas o discurso sobre a cultura muda mais facilmente" (entrevistado A).

Semelhantemente ao que Proulx (2003) sistematicamente defende, os processos de reforma administrativa devem encarnar os aspectos regionais em suas formas de implementação. Da mesma maneira, a administração pública deve refletir os aspectos culturais da sociedade em torno da qual ela vive. É exatamente o que consta em uma das publicações da secretaria do conselho do tesouro, que descreve o que segue: "Um meio de trabalho à imagem da sociedade de Quebec: $\mathrm{O}$ acesso à igualdade no emprego na função pública de Quebec" (SCT, 2009, p. 3). Neste sentido, a busca pela igualdade de condições que se destinam a todos os grupos minoritários nesta sociedade, parece produzir algum efeito na administração pública. Iniciado em 1980, com a Política de igualdade no emprego para as mulheres na função pública de Quebec (SCT, 2009, p. 5), esse processo é estendido a outros grupos, tais como deficientes físicos, imigrantes, entre outros.

Pesquisa realizada sobre os quadros de deputados e ministros aponta que, entre 1973 e 2006, a quantidade de representantes femininas aumentou bastante, passando de uma deputada em 1973 para 23 em 1994 e para 38 em 2006. Da mesma forma o número de ministras salta de uma em 1973, para 5 em 1994 e para 10 em 2006. Diz mais: "O período de 1973 a 2006 testemunha a evolução em matéria 
de representação feminina na Assembleia Legislativa da província de Quebec (Dallaire, 2007, p. 143). Isso demonstra um processo de mudança na perspectiva da participação feminina na administração pública. Da mesma forma, Dallaire (2007) mostra que o número de mulheres em postos da alta administração no governo de Québec vem aumentando significativamente.

O aumento significativo da quantidade de mulheres que ocorre tanto nas funções executivas da administração pública, como no legislativo, reflete aspecto importante da influência da sociedade sobre os processos de mudança cultural nas organizações. Dallaire (2007) demonstra que entre os anos de 1976 e 2005, a participação de mulheres de 15 anos ou mais no mercado de trabalho, saltou de $41,4 \%$ para $59,9 \%$ das mulheres ativas, enquanto, no mesmo período, a taxa de homens ocupados se reduziu de $76,7 \%$ para $71,4 \%$. Assim sendo, é natural que os movimentos que ocorrem na sociedade acabem por afetar diretamente o comportamento dos gestores dentro da administração pública. Neste sentido, um trecho da entrevista do entrevistado B reforça este aspecto, porque, segundo ele, "a cultura de uma organização muda, quando a cultura da sociedade muda, ou quando o sistema de referências da sociedade sofre algum processo de mudança" (entrevistado B).

A descrição do entrevistado B reforça também a abordagem feita por Rodrigues (2006) sobre processos de mudança cultural em organizações. Esta autora conclui que internamente as culturas são passíveis de mudança, quando existe ambiente institucional em torno da organização que a pressiona em direção do conjunto de princípios que sustentam estas instituições. Neste sentido, já que a sociedade de Québec está em processo de transformação, que inclui aumento da quantidade de mulheres no mercado de trabalho e em postos de comando (Dallaire, 2007), é possível que este mesmo processo comece a afetar o funcionamento das organizações públicas.

O tema da igualdade de condições é representado pelo discurso oficial, presente nas publicações do governo. É o processo de convencimento da sociedade de que o governo estaria interessado em modificar as condições em que vivem os grupos minoritários. A figura de pessoas negras, deficientes, sorridentes e bem vestidas em supostos ambientes de trabalho é apresentada para reforçar o discurso do tema da igualdade de condições. É verdade que esse processo discursivo, como demonstra Fiorin (2008), funciona como processo de convencimento (ou de manipulação) de que a prática cotidiana representa os discursos das publicações oficiais. Ainda sobre esta reorientação, na própria sociedade em Quebec, no campo dos gestores, Dupuis $(2008$, p. 32) sugere que "se nota uma forte feminilidade dos gestores em Quebec, o que significa uma tendência à igualdade, à fluidez entre os sexos".

Outro valor que ganha espaço nos discursos dos gestores e do governo é a profissionalização. Este tema tem duas importantes linhas: uma que revela o esforço de capacitação da mão de obra e a outra que procura minimizar as influências externas nos processos administrativos, principalmente a influência político-partidária. Certo é que não se defende a dicotomia entre política e administradores, como se pensa na burocracia weberiana, mas se busca uma forma intermediária, em que a profissionalização possa permitir minimizar os impactos negativos dessas ações. É importante que a inter-relação exista e que ela possa proporcionar uma ação conjunta cujo objetivo principal é o atendimento das demandas da sociedade. Broudreau (2009, p. 109) afirma:

O fato de que os papéis do político e do administrador no seio de um ministério ou do governo sejam diferentes e não devam ser confundidos, não impede, mas, pelo contrário, exige que uma colaboração estreita e funcional se instaure entre os dois.

No que se refere a essa estreita relação entre as duas dimensões, podem surgir algumas preocupações, uma vez que nem sempre os eleitos se comportam de forma coerente com a ética esperada dos gestores públicos. Por exemplo, Boisvert (2003) publica uma análise sobre a cultura política do Canadá, com alguns exemplos do Québec. Seu trabalho visa mostrar como os eleitos têm tido comportamentos no mínimo duvidosos quanto à questão ética. Poder-se-ia pensar que isto ocorreu há muitos anos, e que a sociedade em Québec está livre dos males políticos que ocorrem em outras nações. Entretanto os fatos recentes publicados quase diariamente na imprensa provam o contrário. Essas constatações devem levar os pesquisadores e administradores públicos a refletirem sobre os 
limites do estreitamento entre as ações políticas e a administração pública. Como menciona Proulx (2005), é necessário reconhecer a importância da política para a gestão, desde que ela se limite ao que concerne à definição das demandas, deixando as ações operacionais a cargo dos gestores e funcionários públicos.

Uma vez discutido o aspecto que concebe, em certa medida, uma limitação ao poder político de gerenciar a administração pública, retorna-se à discussão para a profissionalização no setor público em Québec. Manifestada como uma das questões importantes da nova gestão pública, a profissionalização da administração pública deveria ser um valor defendido por seus membros. Neste caso, é possível perceber alguns sinais de que a profissionalização tem sido valorizada. A capacitação e formação são os primeiros requisitos para profissionalizar uma administração. Parcerias com Universidades, criação de cursos internos, entre outros, como a criação do centro de expertise do Conselho do Tesouro reforçam essa perspectiva: "A criação do centro de expertise em gestão de recursos humanos se inscreve ... a fim de fazer da capital nacional o centro estratégico de uma nova função pública" (SCT, 2010, p. 2).

Veem-se, nas figuras dos cursos, professores especializados e expertise, o tema frequente da profissionalização da administração pública. Entre as razões para esta nova orientação destaca-se: "a situação que prevaleceu no governo de Quebec depois de vários anos (diminuição do número de empregados e pouco recrutamento de pessoal novo) não favoreceu verdadeiramente as práticas individuais de desenvolvimento de carreira" (Guay, Rinfret, \& Marais, 2002, p. 13). Nesse contexto são construídos os discursos da necessidade de patrocinar, na função pública, todas as ações indispensáveis para que ela possa dar o salto de qualidade necessário, dentro das perspectivas da reforma administrativa. As figuras de pessoas felizes, bem vestidas, bem como os discursos de oportunidade, crescimento e desenvolvimento profissionais nas publicações do governo, marcam a construção de um discurso que reflete o tema profissionalização do servidor público.

Outra medida que faz efeito sobre a construção da profissionalização é a forma como se efetuam as promoções e o preenchimento dos cargos na administração pública. Busca-se, neste processo, fornecer condições iguais para os indivíduos que pretendam adquirir funções mais elevadas. As regras são importantes, tanto para o ingresso no setor público como para a progressão na carreira. Se a formação profissional e o mérito são valorizados, as pessoas vão passar a perceber, como valor importante o grau de profissionalização que se preconiza nestas organizações. Bernier (2003) destaca que

para favorecer a execução desta missão institucional, a igualdade de acesso aos quadros da função pública, para todos os cidadãos que habitam no território da província de Quebec, é garantida, em virtude de uma regra do mérito, prevista em lei. Esta regra preside os processos de contratação e, ao longo da carreira, os concursos permitem uma mobilidade vertical (p. 5).

Além do que descreve Bernier (2003), o governo de Quebec, por meio do Conselho do Tesouro, implementou a estratégia para admissão de novos gestores, que consiste em etapas formais de formação e seleção. Mais uma vez, a figura dos cursos e estratégias de promoção é utilizada para reforçar o tema da profissionalização. Após os processos seletivos, esta estratégia de seleção permite formar um banco de dados com os indivíduos que estão aptos para determinados cargos e utilizá-lo para selecionar os gestores. Segundo o governo, "é a partir desta lista que os ministérios e os organismos poderão selecionar os futuros gestores, cujo perfil corresponde melhor às características do emprego a assumir" (SCT, 2004, p. 2).

Este critério de promoção e seleção de quadros serve a diversos propósitos. Minimiza a pressão partidária sobre a administração pública, tornando verdade o que Proulx (2005) constatou na visão dos diretores de recursos humanos. Favorece também a profissionalização, na medida em que oferece aos indivíduos oportunidades de crescimento profissional pautado pelo mérito e, por fim, contribui para que os indivíduos mantenham constante busca por conhecimento, já que seu processo avaliativo depende também do conjunto de conhecimentos que ele possui. $\mathrm{O}$ fato de o processo de seleção ser efetuado em colaboração com a ENAP, organização externa, ajuda a melhorar a sua credibilidade. 
Nas perspectivas da reforma administrativa, a qual concebe um grau de liberdade dos gestores, bem como a necessidade de criatividade para buscar as melhores soluções, o controle direto dos indivíduos assume dimensão totalmente relativizada. A reforma administrativa pressupõe novos controles dos gestores, que deixam aquele paradigma burocrático, para pensarem em gestão participativa, com autonomia (Mazouz, 2008), exercem uma liderança coletiva (Lemay, 2008), com características de uma liderança ajustada aos novos modelos organizacionais.

Nesta mesma linha, outros trabalhos de Proulx $(2005,2008)$ demonstram que os discursos de compartilhamento do poder estariam em desenvolvimento. Mediante pesquisa qualitativa, foram feitas algumas entrevistas que demonstram essa percepção: "não se trata de confiar a cada um tarefas extremamente precisas, porque elas são pessoas suficientemente qualificadas para determinar por elas próprias, em função de seu conhecimento, de sua experiência, os meios, antes das tarefas, que precisarão utilizar para alcançá-las" (Proulx, 2008, p. 86).

O tema da delegação ganha importância com as figuras dos sistemas de informação e com as reuniões dos diversos empregados, para discussão das estratégias. Aparecem novas habilidades relacionais que os obrigam a abrir mão do poder, em busca de novas formas de alcançar os resultados organizacionais. Decorre dessa nova característica a valorização das relações pessoais. De início, se percebia um golpe na cultura burocrática, caracterizada pela impessoalidade. Assim, com o foco dirigido às pessoas, os gestores públicos também deveriam dedicar parte do seu tempo para cuidar das relações pessoais nas organizações. Poder-se-ia chamar essa busca de melhoria das relações pessoais uma como tentativa de se criar o mito da grande família, ou esprit Maison, na denominação de Sainsaulieu (1977). Busca-se neste processo o fortalecimento das relações interpessoais, no tempo em que se fortalecem os valores organizacionais, como declara o documento Fonction Publique 2000 (MAS, 1990).

O trabalho de Sainsaulieu (1977) talvez represente a funcionalidade da criação de alguns mitos nas organizações. Este autor entende o mito "como instrumento para fazer os dominados interiorizarem sua impotência, em nome do mito da natureza humana, rica em desigualdades e em influências do modelo familiar de dependência" (Sainsaulieu, 1977, p. 386). Neste sentido, o papel do mito a ser criado pelas organizações teria o objetivo maior de congregar os indivíduos em torno de princípios, que os tornariam menos incentivados a questionar determinadas ações das organizações. Assim, as críticas construídas por Aktouf (1990) devem ser consideradas como importantes elementos de reflexão. Para finalizar, Sainsaulieu (1977, p. 386) acrescenta, com muita propriedade, "se a solução autogerencial tem, novamente, algo mítico, é porque ela nega as relações de força que nascem da distribuição do poder de decisão".

De qualquer forma, no caso da administração publica de Québec, esta orientação parece também ser elemento de interesse. Basta ver as descrições constantes nas publicações e relatórios, bem como as concepções dos autores como Lemay (2008), Mazouz (2008), Proulx (2009): eles consideram que a função da liderança, entre outras, é de tornar as relações interpessoais suficientemente agradáveis para dar à organização a capacidade de ação para o alcance dos resultados. Afirma o governo de Québec no seu plano de ação para 2004-2007: "esta reunião tem por objetivo fazer valer as competências dos membros dos grupos-alvo e oferecer instrumentos de gestão para melhor compreender e gerir as relações humanas em um contexto de diversidade" (SCT, 2004, p. 18).

No trabalho de Proulx $(2008,2009)$, a importância do gestor como o articulador das relações humanas toma corpo. Os resultados demonstram uma evolução da percepção dos gestores desse seu novo papel. É evidente que esta mudança não pode ser vista de forma simples, sem considerar os aspectos do controle da força de trabalho. E é neste sentido que a crítica de Sainsaulieu (1977) se aplica: "se uma nova solução mítica relacionada com o poder nas relações de trabalho nasce, é porque um novo sistema de dominação está se instaurando no contexto das organizações" (Sainsaulieu, 1977, p. 387).

Além dos resultados quantitativos, demonstrados por Proulx e Bière (2005), outras manifestações podem ser encontradas nas suas pesquisas. No caso dos diretores de recursos humanos, 
algumas constatações reforçam o caráter interesseiro dessa forma de abordagem: "é verdade que percebemos que passamos bastante tempo na relação com o outro, a relação humana ... Quanto mais a relação humana é boa, mais podemos solicitar coisas que são perfeitas, em termos de qualidade de trabalho" (Proulx, 2008, p. 87). É necessário levar em conta também a afirmação seguinte: "todas as alterações efetuadas têm produzido uma mudança no discurso desses gestores; mas a cultura, de fato, mudou muito pouco, porém os discursos têm se modificado, principalmente no nível dos gestores" (Entrevistado A).

Um último critério que merece comentários é o aumento da qualidade dos serviços prestados ao cidadão. Este objetivo envolvia todos os ministérios, e duas ações tornaram-se importantes neste contexto. A primeira era definir e apresentar ao público a declaração de serviços ao cidadão, documento publicado pelo governo, no qual constam os seus compromissos com a qualidade dos serviços prestados à comunidade, e em seguida criar um sistema de avaliação que permitisse que o governo fosse avaliado pelos serviços que ele presta. Neste sentido, declara o governo de Quebec:

A lei sobre administração pública, sancionada em maio de 2000, vem reafirmar esta prioridade acordada pela Administração governamental com a qualidade dos serviços prestados aos cidadãos. Esta lei precisa notadamente que, se eles fornecem diretamente alguns serviços à população, os ministérios e os organismos devem levar em conta as expectativas expressas pelos cidadãos em função dos recursos disponíveis. Mas a lei vai mais além, pois ela torna obrigatória a publicação de uma declaração de serviços aos cidadãos, com o termo cidadão designando tanto o cidadão como as empresas (Services Québec, 2009, p. 3).

O governo de Québec implementou as ações formais, tanto no sentido de disponibilizar a declaração como no sentido de avaliar a qualidade dos serviços. Por tratar-se de atividade que engloba todas as organizações públicas, não é possível discutir aqui todos os resultados das avaliações. Entretanto, parece interessante mencionar os resultados do Services Québec, porque este lida com um público diversificado. Além disso, seus dados são apresentados comparando o resultado médio de todos os ministérios de Quebéc. O Services Québec é um órgão do governo de Québec encarregado de prestar serviços à sociedade, incluindo, por exemplo, os registros de nascimento.

Em todos os órgãos, a qualidade dos serviços é avaliada de duas maneiras. A primeira, em função de metas de atendimento definidas. Definem-se tempos de respostas por demandas via internet, cartas e atendimento pelo telefone. Neste quesito, o Services Québec atende adequadamente às metas predefinidas (SCT, 2009). A segunda forma de avaliação consiste em fazer avaliações dos serviços de satisfação do cliente. Interessante notar o empenho desta organização no que se refere à quantidade de avaliações realizadas no período de 2008-2009. Oito sondagens foram realizadas no período, o que pode configurar-se como verdadeira preocupação com a percepção do cliente e com os serviços prestados por este organismo. Uma análise permite verificar que todos os órgãos governamentais publicam a declaração de serviços ao cidadão e a maioria deles faz avaliação de satisfação da clientela.

\section{Conclusões}

Este trabalho teve como objetivo analisar os efeitos da reforma administrativa sobre a cultura organizacional das organizações públicas da província de Quebec, Canadá. Utilizando a análise dos discursos, buscou-se identificar sinais de mudança cultural, já que um dos pressupostos da reforma, disseminado pelos reformadores, era a necessidade de mudança cultural como condição para o sucesso organizacional.

Diante disto algumas constatações foram feitas. Em primeiro lugar, destaca-se uma abordagem funcionalista da cultura, na medida em que os autores e os gestores percebem a cultura como elemento de sucesso, que pode ser apreendida por métodos quantitativos, como destacado por autores como 
Schein (2004), Deal e Kennedy (2000). Se, por um lado, estudos quantitativos facilitam o tratamento dos dados, deixa-se, por outro, de apreender sentidos que não são facilmente percebidos, já que a cultura também compreende elementos localizados nos níveis mais profundos da compreensão humana (Alvesson, 2007; Geertz, 1989).

Outra constatação das abordagens utilizadas e analisadas pelos autores é a concepção da necessidade de estudos comparados para a compreensão da cultura organizacional. Os autores advogam que a apreensão da cultura é mais adequada por este método, já que os indivíduos, dentro de sua própria cultura, não conseguem mais um distanciamento suficiente para perceberem, de fato, quais são os seus reais valores, uma vez que estes já foram internalizados ao longo de suas histórias de vida. Os trabalhos de Proulx (2003, 2009), Dupuis (2008), Dupuis e Davel (2004) mostram esta perspectiva.

Constatou-se também que há uma tendência de diminuição das pesquisas sobre o constructo cultura organizacional no setor público. Diferente do que se percebe na iniciativa privada, os pesquisadores da cultura organizacional não dedicam o mesmo esforço para a compreensão dos processos culturais em organizações públicas. A busca realizada para este trabalho gerou uma quantidade limitada de títulos, principalmente de pesquisas mais recentes. Esta tendência pode ser confirmada pelas entrevistas dos entrevistados A e B, considerando que, em primeiro lugar, os estudos culturais teriam sido substituídos pelos estudos sobre sistemas de gestão, já que, ao interferir nestes, a cultura acaba sendo afetada (Entrevistado B). Em segundo lugar, a cultura parece ser difícil de ser modificada. Além disso, talvez no início do processo de reforma, tenha havido certo modismo sobre a compreensão da cultura organizacional e seus efeitos sobre o sucesso organizacional (Entrevistado A).

A partir das análises realizadas, este trabalho permitiu também verificar como, ao longo do tempo, é possível perceber tendências a mudanças na cultura organizacional no setor público. Diferentemente dos argumentos, mesmo na administração pública de Quebec, como foi o caso do entrevistado A, a cultura de fato pode sofrer processos de mudanças, em função dos artefatos e processos que se vão inserindo nestas organizações. Por isso valores que antes estavam ausentes nos discursos dos gestores, começaram a habitar as suas representações sociais, como é o caso da igualdade, delegação, flexibilidade, autonomia, valorização do cidadão, qualidade de serviços e profissionalização.

Percebeu-se que estes processos de mudança são possíveis, quando se possui um conjunto de instituições em torno dessas organizações, que exercem o papel de incentivador das mudanças internas. No caso em análise, o ambiente institucional, constituído por outras organizações, como universidades, governo, Assembleia Legislativa, e mais fortemente a própria sociedade, se apresenta como o maior sinalizador das necessidades de mudança no setor público de Quebec. Conforme descreve Rodrigues (2006), as mudanças internas são favorecidas por pressões institucionais, significando que a existência de um ambiente institucional aliado dos novos valores favorece a mudança cultural nas organizações públicas.

Desta forma, a própria mudança na sociedade de Quebec, verificada pelo aumento da formação educacional dos indivíduos (Dallaire, 2007), a transformação observada no comportamento dos cidadãos (Dupuis \& Davel, 2004) e nos aspectos da inserção das mulheres e das minorias no mercado de trabalho (Dallaire, 2007) pressionam as organizações, obrigando-as a adotarem novos padrões de comportamento e valores. Da mesma forma, as universidades que possuem cursos de graduação, pósgraduação, com mestrados e doutorados de administração pública, como é o caso da ENAP, contribuem para fortalecer o ambiente institucional, que fornece às organizações públicas indivíduos potencialmente mais bem preparados. Estes, associados aos processos de seleção de gestores de forma meritocrática, favorecerão o abandono de práticas clientelistas, para substituí-las pela profissionalização da gestão pública naquela província.

Assim sendo, como este trabalho procurou defender, a mudança cultural no setor público é possível, desde que existam instrumentos capazes de favorecer o controle social destes processos de mudança. No caso em análise, o fortalecimento das instituições que exercem controle sobre a administração pública contribuiu significativamente para a percepção que se tem da mudança cultural 
na administração pública de Quebec. Logo, o que se pode inferir é que os processos de mudança cultural são favorecidos pelos fatores também localizados no exterior da organização; neste sentido, os argumentos de que a reforma gerencial não é democrática, como defende Paes de Paula (2005), de fato ajuda a explicar o insucesso de processos de mudanças apoiados na reforma gerencial em países como o Brasil, por exemplo.

Por fim, este texto lança luzes sobre o argumento de que é possível contribuir com mudanças culturais no setor público, desde que não se atribua a este processo o caráter meramente funcionalista e autoritário do próprio processo, mas que, apoiados nas instituições (Rodrigues, 2006) e na participação da sociedade (Paes de Paula, 2005), os processos sinalizem os benefícios sociais advindos de tais mudanças.

\section{Artigo recebido em 19.10.2010. Aprovado em 16.06.2011.}

\section{Referências}

Aktouf, O. (1990). Le symbolism et la culture d'entreprise. Des abus conceptuels aux leçons du terrain. In J. F. Chanlat (Coord.), L'individu dans l'organasition (pp. 40-82) Quebec: Les Presses de l'université.

Alvesson, M. (2004). Organizational culture and discourse. In D. Grant, C. Hardy, C. Oswick, \& L. L. Putnam (Eds.), The sage handbook of organizational discourse (pp. 317-335). London: Sage Publications.

Alvesson, M. (2007). Understanding organizational culture. London: SAGE Publications.

Bernier, P. (2003). Identité et modernité de la fonction publique québécoise. Coup d'oeil, 9(3), 2-12.

Boisvert, G. (1997). La performance du secteur public reliée aux compétences de ses gestionnaires. In M. M. Guay (Org.), Performance et secteur public: réalités, enjeux et paradoxes (pp. 34-67). Sainte-Foy: Presses de l'Université du Québec.

Boisvert, Y. (2003). L'éthique et culture politique: sombre bilan pour 2002. In R. Côté \& M. Venne (Coords.), L'annuaire du Québec 2003. Toute l'année politique, sociale, économique et culturelle (pp. 46-59). Montréal : Fidès.

Bonnafous-Boucher, M. (2005). Anthropologie et gestion. Paris: Economica.

Broudreau T. J. (2009). La décision politique: le point de vue d'un haut fonctionnaire. In D. Proulx (Org.), Management des organisations publiques. Théorie et applications (2nd ed., pp. 101111). Québec: Presses de l’Université du Québec.

Chanlat, A. (1984). Gestion et culture d'entreprise: le cheminement d'Hydro-Québec. Québec: Editions Québec/Amérique.

Davel, E., Dantas, M., \& Vergara, S. C. (2008). Culture et gestion au Brésil. In E. Davel, J. P. Dupuis, $\&$ J. F. Chanlat (Orgs.), Gestion en contexte interculturel: approches, problematiques, pratiques et plongées (pp. 1-35). Québec: Les presses de l’Université Laval.

Davel, E., Dupuis, J. P., \& Chanlat, J. F. (2008). Introduction. In E. Davel, J. P. Dupuis, \& J. F. Chanlat (Orgs.), Gestion en contexte interculturel: approches, problematiques, pratiques et plongées (pp. 1-21). Québec: Les presses de l'Université Laval.

Deal, T. E., \& Kennedy, A. (2000). Corporate cultures. The rites and rituals of corporate life. Cambridge: Basic Books. 
Dallaire, L. (2007). D'égale à égal? Un portrait statistique des femmes et des dommes. Québec: Secrétariat à la condition féminine. Recuperado em 14 maio, 2010, de http://www.scf.gouv.qc.ca/fileadmin/publications/egale-a-egal.pdf

Dupuis, J. P. (1990). Anthropologie, culture et organisation. Vers un modèle constructiviste. In J. F. Chanlat (Coord.), L'individu dans l'organisation. Les dimensions oubliées (pp. 533-552). Québec : PUL-Eska.

Dupuis, J. P. (2008). Culture et gestion au Québec: entre cultures latine, anglo-saxonne et nordique. In E. Davel, J. P. Dupuis, \& J. F. Chanlat (Orgs.), Gestion en contexte interculturel: approches, problematiques, pratiques et plongées (pp. 1-45). Québec: Les presses de l'Université Laval.

Dupuis, J. P., \& Davel, E.( 2004). Gestion internationale et cultures du nouveau monde: l'ambiguïté et l'adaptabilité comme véhicules sociaus au Brésil et au Québec (Cahier de recherche), Montréal, École des Hautes Études Commerciales de Montréal.

Fiorin, J. L. (2007). Linguagem e ideologia (8a ed.). São Paulo: Ática.

Fiorin, J. L. (2008). Elementos de análise do discurso (6a ed.). São Paulo: Contexto.

Geertz, C. (1973). The interpretation of cultures. New York: Basic books.

Geertz, C. (1989). A interpretação das culturas. Rio de Janeiro: LTC.

Grant, D., Hardy, C., Oswick, C., \& Putnam, L. (2004). Introduction: organizational discourse: exploring the field. In D. Grant, C. Hardy, C. Oswick, \& L. Putnam (Eds.), The sage handbook of organizational discourse (pp. 1-3). London: Sage Publications.

Guay, M.-M., Rinfret, N., \& Marais, A. D. (2002). Mentorat et développement de carrière: réalités, enjeux et conditions de succès dans la fonction publique québécoise (Rapport de Recherche), Québec, CA, Secrétariat du Conseil du Trésor. Recuperado em 10 maio, 2010, de http://www.tresor.gouv.qc.ca/fileadmin/PDF/publications/mentor_rapp_rech_02.pdf

Hofstede, G. (1991). Culturas e organizações: compreender a nossa programação mental. Lisboa: Edições Silabo.

Hofstede, G. (2001). Culture's consequences: comparing values, behaviors, institutions, and organizations across nations (2nd ed.). London: Sage Publications.

Julien, G. (1993). Les valeurs collectives de gestion dans la fonction publique Québécoise: la perception des cadres. Revue d'Administration Publique du Canada, 36(3), 319-348. doi: 10.1111/j.1754-7121.1993.tb01957.x

Kotter, J. P., \& Heskett, J. L. (1992). Corporate culture and performance. New York: The Free Press.

Lei n. 82, de 25 de maio de 2000. (2000). Loi sur l'administration publique. Québec. Recuperado em 15 maio, 2010, de http://www2.publicationsduquebec.gouv.qc.ca/dynamicSearch/telecharge.php?type=2\&file=/A_ 6_01/A6_01.html

Lemay, L. (2008). Le devoir d'être stratège. In B. Mazouz (Orgs.), Le métier de gestionaire public à l'aube de la gestion par résultats: nouveaux rôles, nouvelles fonctions, nouveaux profils (pp. 299-332). Québec : Presses de l'Université du Québec.

Lozeau, D. (2005). Le cas d'une mouvance managérialiste laborieuse dans des bureaucraties professionnelles publiques. In L. Lemire, D. Proulx, \& L. Cooremans (Eds.), Modernisation de l'État et gestion des ressources humaines: bilan et perspectives (pp. 101-123). Québec: Haute École Francisco Ferrer. 
Machado-da-Silva, C. L., \& Nogueira, E. E. S. (2000). Instituições, cultura e identidade organizacional. Curitiba: Cromo Editora.

Martin, J. (2002). Organizational culture: mapping the terrain. London: Sage Publications.

Mazouz, B. (2008). Vers l'émergence du véritable gestionnaire public: de l'acte administratif à la performance managériale. In B. Mazouz (Org.), Le métier de gestionnaire public à l'aube de la gestion par résultats: nouveaux rôles, nouvelles fonctions, nouveaux profils ( $\mathrm{pp} .15-48$ ). Québec: Presses de l'Université du Québec.

Mazouz, B., \& Tardif, M. J. B (2009). À propos de la performance L'Arlésienne de la sphère publique. In D. Proulx (Org.), Management des organisations publiques. Théorie et applications (2nd ed., pp. 31-61). Québec: Presses de l’Université du Québec.

Ministère des Approvisionnements et Services. (1990). Fonction Publique 2000: le renouvellement de la fonction publique $d u$ Canada. Recuperado em 15 maio, 2010, de http://publications.gc.ca/site/fra/20991/publication.html

Paes de Paula, A. P. (2005). Por uma nova gestão pública. Rio de Janeiro: Editora FGV

Proulx, D. (2003). Le management par résultats: une perspective transculturelle. International Management, 7(4), 39-48.

Proulx, D. (2005). Modernisation et valeurs de gestion des administrations publiques: cas américais et africains. In L. Lemire, D. Proulx, \& L. Cooremans (Eds.), Modernisation de l'État et gestion des ressources humaines: bilan et perspectives Québec - Belgique (pp. 125-140). Québec: Heute École Francisco Ferrer.

Proulx, D. (2008). Le gestionnaire public de demain et les valeurs qui supportent son action. In B. Mazouz (Org.), Le métier de gestionnaire public à l'aube de la gestion par résultats: nouveaux rôles, nouvelles fonctions, nouveaux profil (pp. 73-96). Québec: Presses de l'Université du Québec.

Proulx, D. (2009). Les approches em management: la pertinence de traiter des approches em management. In D. Proulx (Org.), Management des organisations publiques. Théorie et applications (2nd ed., pp. 5-30). Québec: Presses de l'Université du Québec.

Proulx, D., \& Bière, S. (2005). La réforme administrative au gouvernement du Québec: étude du processus de changement sur la culture organisationnelle. Revue d'Administration publique du Canada, 48(1) 53-72. doi: 10.1111/j.1754-7121.2005.tb01598.x

Rodrigues, S. B. (2006). The political dynamics of organizational culture in an institutionalized environment. Organization Studies, 27(4), 537-557. doi: 10.1177/0170840605059454

Sackmann,S. A. (1992). Culture and subcultures: an analysis of organizational knowledge. Administrative Science Quarterly, 37(1), 140-161.

Sahlins, M. (1976). Culture and practical Reason. Chicago: University of Chicago Press.

Sainsaulieu, R. (1977). L'identité au travail. Paris: Presses de la Fondation Nationale des sciences politiques.

Sainsaulieu, R. (2001). Des société en mouvement: la ressource des institutions intermediares. Paris: Desclée de Brouwer.

Schein, E. (2004). Organizational culture and leadership. San Francisco: Jossey-Bass. 
Schwartz, S. H. (1994). Are there universal aspects in the structure and contents of human values? Journal of Social Issues, 50(4), 19-45. doi: 10.1111/j.1540-4560.1994.tb01196.x

Secrétariat du Conseil du Trésor. (2004). Plan de gestion des ressources humaines 2004-2007 (Rapport de planification), Québec, CA, Auteur. Recuperado em 15 maio, 2010, de http://www.tresor.gouv.qc.ca/fileadmin/PDF/publications/plan_gest-rh_04-07.pdf

Secrétariat du Conseil du Trésor. (2009). Accès à l'égalité en emploi dans la fonction publique du Québec. Recuperado em 10 maio, 2010, de http://www.tresor.gouv.qc.ca/fr/ressourceshumaines/acces-a-legalite-en-emploi/

Secrétariat du Conseil du Trésor. (2010). Déclaration de valeurs de l'administration publique québécoise. Recuperado em 15 maio, 2010, de http://www.tresor.gouv.qc.ca/fileadmin/PDF/publications/d/declaration_valeurs.pdf

Services Québec. (2009). Rapport annuel de gestion 2008-2009. Recuperado em 4 maio, 2010, de http://www.gouv.qc.ca/portail/wcm/connect/resources/file/eb032d4ab87d57e/RAG_20082009_Services_Quebec_VE.pdf?MOD=AJPERES

Symons, G. L. (1992). Déconstruction de la culture organisationnelle. Symbolisme et pouvoir au sein de la fonction publique. In R. Parenteua (Org.), Management public: comprendre et gérer les institutions de l'État (pp. 97-114). Québec: Presses de l'Université du Québec. 